\title{
Prediction of high nodal burden in invasive breast cancer by quantitative shear wave elastography
}

\author{
Bo $\mathrm{Li}^{1}$, Xin Zhao ${ }^{2}$, Qiucheng Wang ${ }^{1}$, Hui Jing ${ }^{1}$, Hua Shao ${ }^{1}$, Lei Zhang ${ }^{1}$, Wen Cheng ${ }^{1}$ \\ ${ }^{1}$ Department of Ultrasound, Harbin Medical University Cancer Hospital, Harbin, China; ${ }^{2}$ Department of Surgery, The Second Affiliated Hospital of \\ Harbin Medical University, Harbin, China
}

Contributions: (I) Conception and design: B Li, W Cheng; (II) Administrative support: W Cheng; (III) Provision of study materials or patients: H Jing, H Shao; (IV) Collection and assembly of data: B Li, Q Wang; (V) Data analysis and interpretation: X Zhao, L Zhang; (VI) Manuscript writing: All authors; (VII) Final approval of manuscript: All authors.

Correspondence to: Wen Cheng. Department of Ultrasound, Harbin Medical University Cancer Hospital, 150 Haping Rd, Nangang District, Harbin 150081, China. Email: chengwen69@yahoo.com.

\begin{abstract}
Background: Axillary imaging has been earmarked to forecast high nodal burden [ $\geq 3$ metastatic axillary lymph nodes (ALN)] instead of lymph node metastasis since the Z0011 trial period. We aimed to ascertain the possibility of utilising quantitative shear wave elastography (SWE) to forecast high nodal burden in invasive breast cancer (IBC).

Methods: In our hospital, 324 patients with clinical T1-T2N0 IBC who underwent surgery from June 2020 to October 2020 were analyzed retrospectively. A total of 273 patients $(84.3 \%)$ were categorized as having a limited nodal burden, while 51 patients $(15.7 \%)$ had a high nodal burden. The two groups were compared in terms of clinicopathological traits, ultrasonic features, and SWE values. The diagnostic performance for prediction of high nodal burden with the optimal cutoff values was drawn by SWE value.

Results: The optimal cutoff values for forecasting high nodal burden were as demonstrated: $119.52 \mathrm{kPa}$ for tumor Emax, $97.31 \mathrm{kPa}$ for tumor Emean, 19.38 for tumor Esd, $26.22 \mathrm{kPa}$ for ALN Emax, $19.79 \mathrm{kPa}$ for ALN Emean, 2.32 for ALN Eratio, 3.34 for ALN Esd. Combined with the ratings of sensitivity and specificity, ALN Emax could be chosen as the optimal index if the best diagnostic achievement was contemplated (AUC: 0.856; 95\% CI: 0.802-0.909).

Conclusions: An Emax cutoff $26.22 \mathrm{kPa}$ of ALN, $72 \%$ of women with a high nodal burden of axillary disease would be detected, but if used for clinical decision making, 13\% of women with a limited nodal burden disease would be potentially over treated. This data can allow us to appropriately ascertain this subgroup and can be used as one of the therapeutic implementation resources for patient decision support.
\end{abstract}

Keywords: High nodal burden; limited nodal burden; shear wave elastography (SWE); invasive breast cancer (IBC)

Submitted Jun 01, 2021. Accepted for publication Sep 28, 2021.

doi: 10.21037/qims-21-580

View this article at: https://dx.doi.org/10.21037/qims-21-580

\section{Introduction}

As reported by the newest statistics from the International Agency for Cancer Research (IARC), breast cancer has surpassed all other cancers as the world's most common cancer, posing a significant threat to global public health (1).
The pre-surgery state of the axillary lymph node (ALN) is quite significant in the early stage of breast cancer and will influence the care plan and the type of surgery (2). According to preoperative assessment, patients with no suspicious ALN metastasis by ultrasound or a negative needle biopsy outcome should have a sentinel lymph node 
biopsy (SLNB), which is the gold standard for evaluating ALN metastasis. Axillary lymph node dissection (ALND) is regularly needed if metastatic ALNs have been observed by SLNB $(3,4)$. Due to the American College of Surgeons Oncology Group Z0011 (ACOSOG Z0011) randomized clinical trial (5), the goal of axillary imaging was to forecast high nodal burden ( $\geq 3$ metastatic ALNs) rather than forecast lymph node metastases. This trial has demonstrated that omission of ALND does not affect overall survival in selected patients with early breast cancer who have one or two metastasized sentinel lymph nodes. Forecasting high nodal burden can assist in identifying what kind of initial axillary surgery can overlook the SLNB and undergo ALND specifically and assist in employing neoadjuvant chemotherapy or individualized adjuvant radiotherapy.

While ultrasound is commonly adopted to detect presurgery lymph node metastases, its sensitivity varies from $35 \%$ to $82 \%$, and its specificity ranges from $73 \%$ to $97.9 \%$ (6-8). In several trials, elastography, an imaging technique focused on tissue stiffness or toughness, improved the distinction between benign and malignant lesions in breast tissue (9-11). Strain elastography (SE) and shear wave elastography (SWE) are the two primary methods for determining stiffness. When an external force is applied to a tissue, SE measures how much it deforms (12). The softer the tissue, the more significant the deformation. By assessing the degree of deformation of the different tissues in the image region, an image reflecting the relative toughness of the tissues that could be developed. The outer force that induces the deformity could be from the probe, the respiratory or cardiac motions of the patient. The fundamental theory of SWE is to apply intense signals to stimulate tissues and to produce shear waves perpendicular to the acoustic beam. The velocity of the shear wave differs with the density of the tissue. The velocity increases as the tissue become harder. On the opposite, the softer the tissue, the relatively slow the velocity. SWE offers quantitative assessment as well as a visual colour overlay that displays elastic data in real-time. A connection has been discovered between a higher elasticity value and a higher cancer detection prediction rate. Elastography can forecast lymph node metastasis by evaluating the hardness of breast tumours or lymph nodes $(13,14)$, although there are limited records of the association between SWE and high nodal burden.

In this test, the optimum cutoff value of SWE was calculated for the assessment of high nodal burden by examination of primary breast lesions and lymph nodes. As a result, it will establish the imaging foundation for ALND prejudgment prior to clinical operation. We present the following article in accordance with the STARD reporting checklist (available at https://dx.doi.org/10.21037/qims-21-580).

\section{Methods}

\section{Ethical statement}

The retrospective study was approved by the Institutional Ethics Review of Harbin Medical University Cancer Hospital and aligned with the Helsinki Declaration of 1964 and its corresponding revisions or equivalent ethical principles. The written consent of each patient participating in the research was waived. The information which can disclose the identity of the recipient must be exempted.

\section{Patients}

Eventually, we retrospectively evaluated patients with clinical T1-T2N0 invasive breast cancer (IBC) who underwent surgical procedures in our hospital from June 2020 to October 2020. Exemption criteria are as follows: Patients who have undergone neoadjuvant chemotherapy; Patients with biopsy prior to ultrasound or SWE evaluation; Patients with clinical palpation positive ALN; Patients who sufferers with synchronous bilateral breast cancer. In sufferers with multifocal cancer, the biggest tumor is included. Patients were categorized according to their limited $(<3$ metastatic ALN) or high burden ( $\geq 3$ metastatic ALN) postoperative lymph node pathology. Sufferers with negative sentinel lymph nodes were immediately incorporated in the limited nodal burden group, although no pathological examination of the surviving ALN was undertaken. The flow chart of this study is shown in Figure 1.

\section{Ultrasound and SWE examination}

With a combined 10 years of expertise in breast ultrasound, all of the researchers were experts in breast diagnostic imaging. The ultrasonographic features and SWE parameters were independently assessed by two specialists. The discrepancy was resolved by two other experts joining in to reach a consensus. Ultrasound and SWE experiments were conducted in sufferers with a $2-10$ or $4-15 \mathrm{MHz}$ probe by using the SuperSonic Imagine ultrasound system (Aixplorer, Aixen Provence, France). The ultrasonographic characteristics of primary breast lesions were analysed using 


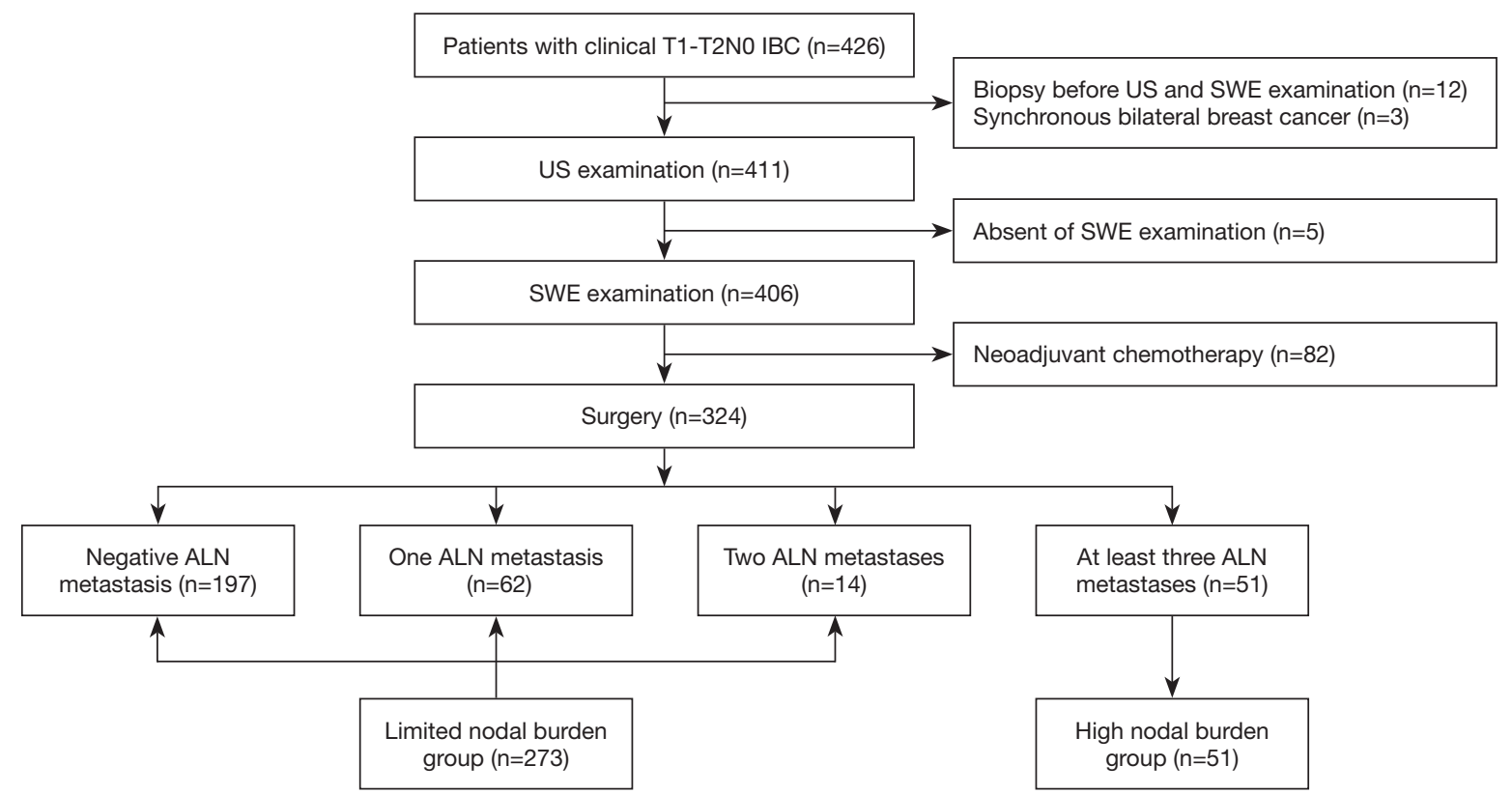

Figure 1 The study flow chart. IBC, invasive breast cancer; US, ultrasound; SWE, shear wave elastography; ALN, axillary lymph node.

the 5th American College of Radiology Breast Imaging Reporting and Data System (BI-RADS) lexicon. While assessing the ultrasound characteristics of the lymph nodes, the long diameter (LD), short diameter (SD), cortical thickness, and sceptical number of ALN have all been documented. If several suspicious lymph nodes are detected, the most suspicious lymph node which with the maximum cortical thickness is registered.

For SWE evaluation, the scale of the elastic color image is set to $0-180 \mathrm{kPa}$. Lesion and accompanying normal tissues are identified as the system region of interest (ROI). The initial fixed Q-Box of $2 \times 2 \mathrm{~mm}^{2}$ was put in the toughest section of the lesion, along with the nearby hard tissue or halo. A second Q-Box with the same scale was positioned outside the lesion in healthy adipose tissue as a comparison. Maximum stiffness (Emax, $\mathrm{kPa}$ ), mean stiffness (Emean, $\mathrm{kPa}$ ), stiffness ratio (Eratio), and stiffness standard deviation (Esd, $\mathrm{kPa}$ ) was reported.

\section{Histopathological evaluation}

Immunohistochemistry was used to determine the condition of the estrogen receptor (ER), progesterone receptor (PR), human epidermal growth factor receptor 2 (Her2), and Ki67 labelling index (LI). When more than $1 \%$ of tumor cells have immunohistochemistry staining, ER and PR state are classified positive (15). HER2 positive is classified as grade
$3+$, and fluorescence in situ hybridization (FISH) is needed for assessment at grade 2+. We assumed Ki-67 to be high expression when $\geq 20 \%$ and under-expression when $<20 \%$.

\section{Statistical analysis}

Statistical analysis was conducted using SPSS 20.0 tools (SPSS Inc., Chicago, IL, USA). For each study outcome, the $\mathrm{P}$ values of the bilateral experiments were used and the test standard was $\alpha=0.05$. For the evaluation of the disparities between the demographic baseline data of distinct lymph node burden groups and the component of the count data (classification index) in the ultrasonic features of the breast, the cases number $(\mathrm{N})$ and the percentage (\%) were utilised in defining and the chi-square method was utilised. If the theoretical frequency is minuscule and satisfies the standard of Fisher exact test criterion, the result of Fisher exact test is accepted; the measurement data for ultrasonic features (e.g., tumor diameter, tumor SWE parameters, and ALN SWE parameters) did not agree with the normal distribution upon verification, so the median (interquartile) was used for description and the Mann-Whitney $U$ test analysis was performed with two independent samples. Odds ratio (OR) and $95 \%$ confidence intervals (95\% CIs) for predicting high nodal burden were calculated with logistic regression analysis. The Receiver operating characteristic (ROC) curve was utilised to evaluate the diagnostic efficacy of distinct 
ultrasonic elastic characteristic parameters for characterising the lymph node burden groups.

\section{Results}

Of 324 cases, $273(84.3 \%)$ were identified as having a limited nodal burden which 197 cases have negative ALN metastasis, 62 cases have one ALN metastasis, and 14 cases have two ALN metastases, while 51 (15.7\%) were categorized as having a high nodal burden. Disparities in clinicopathological features amongst patients with the high and limited nodal burden as demonstrated in Table 1. The disparity in the distribution of Ki-67 and lymphovascular invasion (LVI) between the two classes was highly significant. The high expression of Ki-67 in the high nodal burden group was $68.6 \%$, which was substantially larger than those in the limited nodal burden group (49.5\%); the percentage of LVI in the high nodal burden group was $52.9 \%$, which was considerably higher than in the limited nodal burden group (19.4\%). There were hardly any variations in age, family history of cancer, menopause, histologic type, ER, PR, HER2, P53, and molecular type seen between the two classifications.

Table 2 demonstrates the univariate analysis of the variations in ultrasonic characteristics between the limited nodal burden group and the high nodal burden group. T2 tumor size $(62.7 \%$ vs. $36.6 \%, \mathrm{P}<0.001)$, median tumor diameter (23.0 vs. $18.0 \mathrm{~mm}, \mathrm{P}<0.001)$, spiculated margin (37.3\% vs. $12.1 \%, \mathrm{P}<0.001)$, the combined pattern of posterior characteristics $(11.8 \%$ vs. $6.6 \%, \mathrm{P}=0.038)$, cortical thickness $\geq 5 \mathrm{~mm}(41.2 \%$ vs. $15.4 \%, \mathrm{P}<0.001)$ and suspicious ALN $\geq 3(39.2 \%$ vs. $2.9 \%, \mathrm{P}<0.001)$ in the high nodal burden group were substantial. Additionally, the percentage of $\mathrm{SD}<5 \mathrm{~mm}$ in the high nodal burden group was $23.5 \%$, which was slightly lower than $42.5 \%$ in the limited nodal burden group. There was no variation amongst the two groups in orientation, halo, calcification, tumor vascularity, and ALN LD.

Univariate analysis of SWE parameters between the limited nodal burden group and the high nodal burden group as revealed in Table 3. There are significant variations between the two groups in the median SWE values of Emax $(\mathrm{P}=0.001)$, Emean $(\mathrm{P}=0.002)$, Esd $(\mathrm{P}=0.001)$ derived from tumors. The median SWE values in ALN between the two groups in Emax $(\mathrm{P}<0.001)$, Emean $(\mathrm{P}<0.001)$, Eratio $(\mathrm{P}<0.001)$, Esd $(\mathrm{P}<0.001)$ is statistically important. All SWE parameters of the high nodal burden group were larger than those of the limited nodal burden group.
The factors influencing high nodal burden in univariate analysis were included in the multivariate logistic regression model. The results which are listed in Table 4 showed that LVI $(\mathrm{OR}=6.820, \mathrm{P}<0.001)$, tumor size $(\mathrm{OR}=3.144$, $\mathrm{P}=0.013)$, suspicious number of $\mathrm{ALN} \geq 3(\mathrm{OR}=26.336$, $\mathrm{P}<0.001)$, median $\mathrm{SWE}$ values of $\operatorname{Emax}(\mathrm{OR}=1.032$, $\mathrm{P}=0.002)$ and Emean $(\mathrm{OR}=0.964, \mathrm{P}=0.004)$ in tumor, and median SWE values of Esd in ALN $(\mathrm{OR}=1.298, \mathrm{P}<0.001)$ were independently associated with high nodal burden.

We further evaluated the diagnostic efficiency of SWE for the prediction of high nodal burden group with the optimal cutoff values. The SWE values in the limited nodal burden group and the high nodal burden group were shown in Figure 2. The optimum cutoff value was as follows: $119.52 \mathrm{kPa}$ for tumor Emax, $97.31 \mathrm{kPa}$ for tumor Emean, 19.38 for tumor Esd, $26.22 \mathrm{kPa}$ for ALN Emax, $19.79 \mathrm{kPa}$ for ALN Emean 2.32 for Eratio of ALN, 3.34 for Esd of ALN. The area under the curve (AUC), Sensitivity (Sen), Specificity (Spe), Diagnostic Accuracy (ACC), Positive Predictive Value (PPV), Negative Predictive Value (NPV) with optimum cutoff values are shown in Table 5. In conjunction with sensitivity and specificity scores, Emax of ALN could be chosen as the ideal index if maximum diagnostic performance was considered (AUC: 0.856; 95\% CI: 0.802-0.909). The ROC curve is demonstrated in Figure 3.

\section{Discussion}

In this analysis, high nodal burden group in IBC is associated with clinicopathological criteria, ultrasound characteristics, and tumor or ALN stiffness evaluated by SWE. LVI of the primary breast tumor is regarded as a well-known independent risk factor for axillary nodal metastases (16), the results of our research have shown that LVI has been correlated with an high nodal burden that confirms earlier issued articles $(17,18)$, but the findings of LVI cannot be precisely provided until post-surgery pathology.

In the ultrasonic characteristics, we determined that the spiculated margin of the primary breast lesion was higher in the high nodal burden group, as well as the combined pattern of posterior features, which is seldom recorded in other reports. Tumor size has been documented to be a potential risk for ALN metastases in several studies $(19,20)$. As revealed by our findings, tumor size was an independent predictor for high nodal burden.

Some scientists (21) proposed that axillary ultrasound and needle aspiration biopsy of any suspicious lymph nodes 
Table 1 Disparities in clinicopathological features amongst patients with the high and limited nodal burden

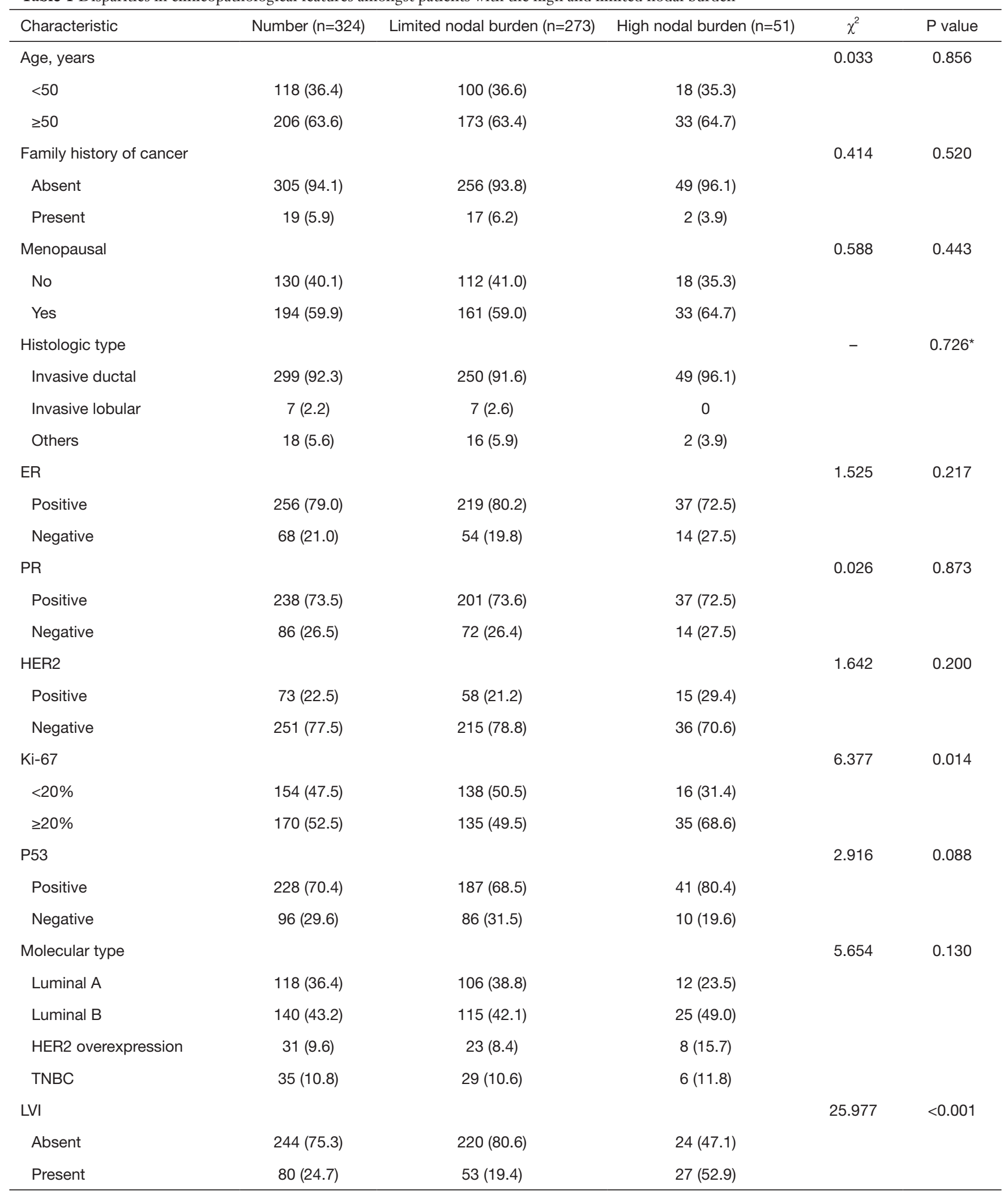

*, Fisher exact probability test results. Data presented as n (\%). TNBC, triple negative breast cancer; LVI, lymphovascular invasion. 
Table 2 Univariate analysis of the variations in ultrasonic characteristics between the limited nodal burden group and the high nodal burden group

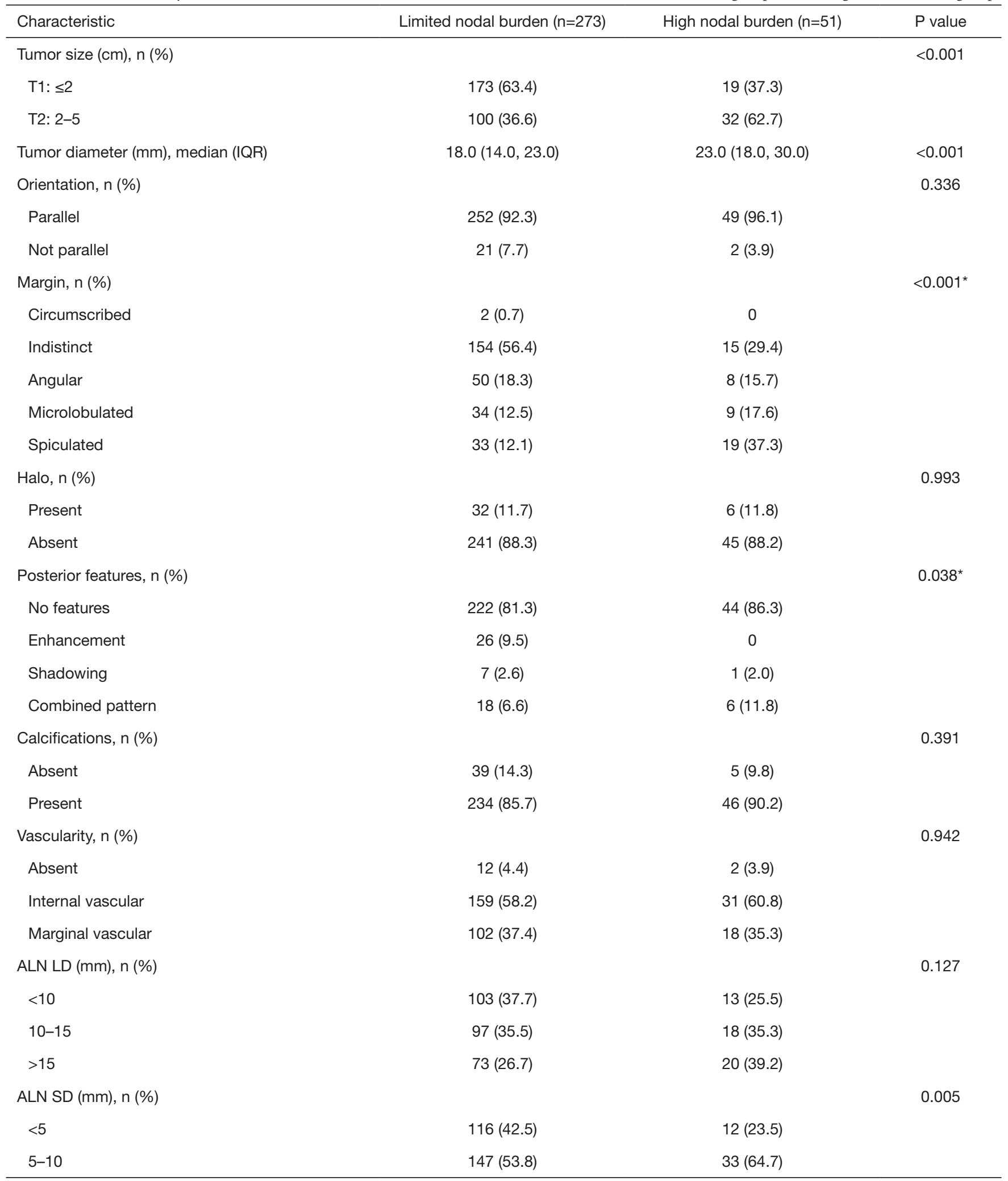

Table 2 (continued) 
Table 2 (continued)

\begin{tabular}{lcc}
\hline Characteristic & Limited nodal burden $(\mathrm{n}=273)$ & High nodal burden $(\mathrm{n}=51)$ \\
\hline$>10$ & $10(3.7)$ & $6(11.8)$ \\
ALN cortical thickness $(\mathrm{mm}), \mathrm{n}(\%)$ & & $9(17.6)$ \\
$<2$ & $143(52.4)$ & $7(13.7)$ \\
$2-3$ & $74(27.1)$ & $5(9.8)$ \\
$3-4$ & $12(4.4)$ & $9(17.6)$ \\
$4-5$ & $2(0.7)$ & $21(41.2)$ \\
$\geq 5$ & $42(15.4)$ & $14(27.5)$ \\
Suspicious number of ALN, $\mathrm{n}(\%)$ & & $8(15.7)$ \\
0 & $212(77.7)$ & $9(17.6)$ \\
1 & $38(13.9)$ & $20(39.2)$ \\
2
\end{tabular}

*, Fisher exact test results. LD, long diameter; SD, short diameter; ALN, axillary lymph nodes.

Table 3 Univariate analysis of SWE parameters between the limited nodal burden group and the high nodal burden group

\begin{tabular}{|c|c|c|c|}
\hline SWE & Limited nodal burden $(n=273)$ & High nodal burden $(n=51)$ & $P$ value \\
\hline Emax, $\mathrm{kPa}$ & $135.5(102.7,164.6)$ & $152.3(127.6,191.4)$ & 0.001 \\
\hline Emean, kPa & $106.7(81.6,129.1)$ & $123.9(102.3,148.3)$ & 0.002 \\
\hline Eratio & $9.7(6.7,13.8)$ & $10.5(8.1,14.3)$ & 0.262 \\
\hline \multicolumn{4}{|c|}{ Median SWE values in ALN } \\
\hline Emax, $\mathrm{kPa}$ & $18.5(13.7,23.6)$ & $36.4(24.2,61.1)$ & $<0.001$ \\
\hline Emean, $\mathrm{kPa}$ & $14.5(10.8,19.5)$ & $27.6(20.2,44.1)$ & $<0.001$ \\
\hline Eratio & $1.8(1.3,2.6)$ & $2.8(2.1,5.2)$ & $<0.001$ \\
\hline
\end{tabular}

Data presented as median (IQR). SWE, shear wave elastography; ALN, axillary lymph nodes; Emax, maximum stiffness; Emean, mean stiffness; Eratio, stiffness ratio; Esd, stiffness standard deviation.

should be excluded so as not to preclude certain patients from axillary protection in the Z0011 trial pathway. While patients with positive percutaneous biopsy appeared to have a high nodal burden (22), other studies (23) showed that almost half of these patients with positive needle-aspiration biopsy received axillary-preservation treatment safely in the post-Z0011 trial period. The correct procedure for integrating axillary ultrasound and needle aspiration biopsy into clinical care remains uncertain.

Lymph nodes with cortical morphological changes as well as hilum absence were considered questionable during an axillary ultrasound test. Morphological variations in the cortex are known to be a sign of metastases since the metastatic cells live in the cortex of the lymph node $(24,25)$. Researches $(26)$ have proved that a larger number of suspicious ALNs is an independent predictive factor 
Table 4 Multivariate logistic regression analysis for prediction of high nodal burden

\begin{tabular}{lcc}
\hline Variable & Odds Ratio (95\% Cl) & P value \\
\hline LVI & $6.820(2.825-17.489)$ & $<0.001$ \\
Tumor size & $3.144(1.293-7.826)$ & 0.013 \\
Suspicious number of ALN & & 0.637 \\
1 & $1.335(0.377-4.283)$ & 0.064 \\
2 & $3.297(0.899-12.272)$ & $<0.001$ \\
$\geq 3$ & $26.336(7.971-96.099)$ & 0.002 \\
Median SWE values of Emax in tumor & $1.032(1.011-1.053)$ & 0.004 \\
Median SWE values of Emean in tumor & $0.964(0.940-0.988)$ & $<0.001$ \\
Median SWE values of Esd in ALN & $1.298(1.117-1.526)$ & \\
\hline
\end{tabular}

LVI, lymphovascular invasion; ALN, axillary lymph nodes; SWE, shear wave elastography; Emax, maximum stiffness; Emean, mean stiffness; Esd, stiffness standard deviation.
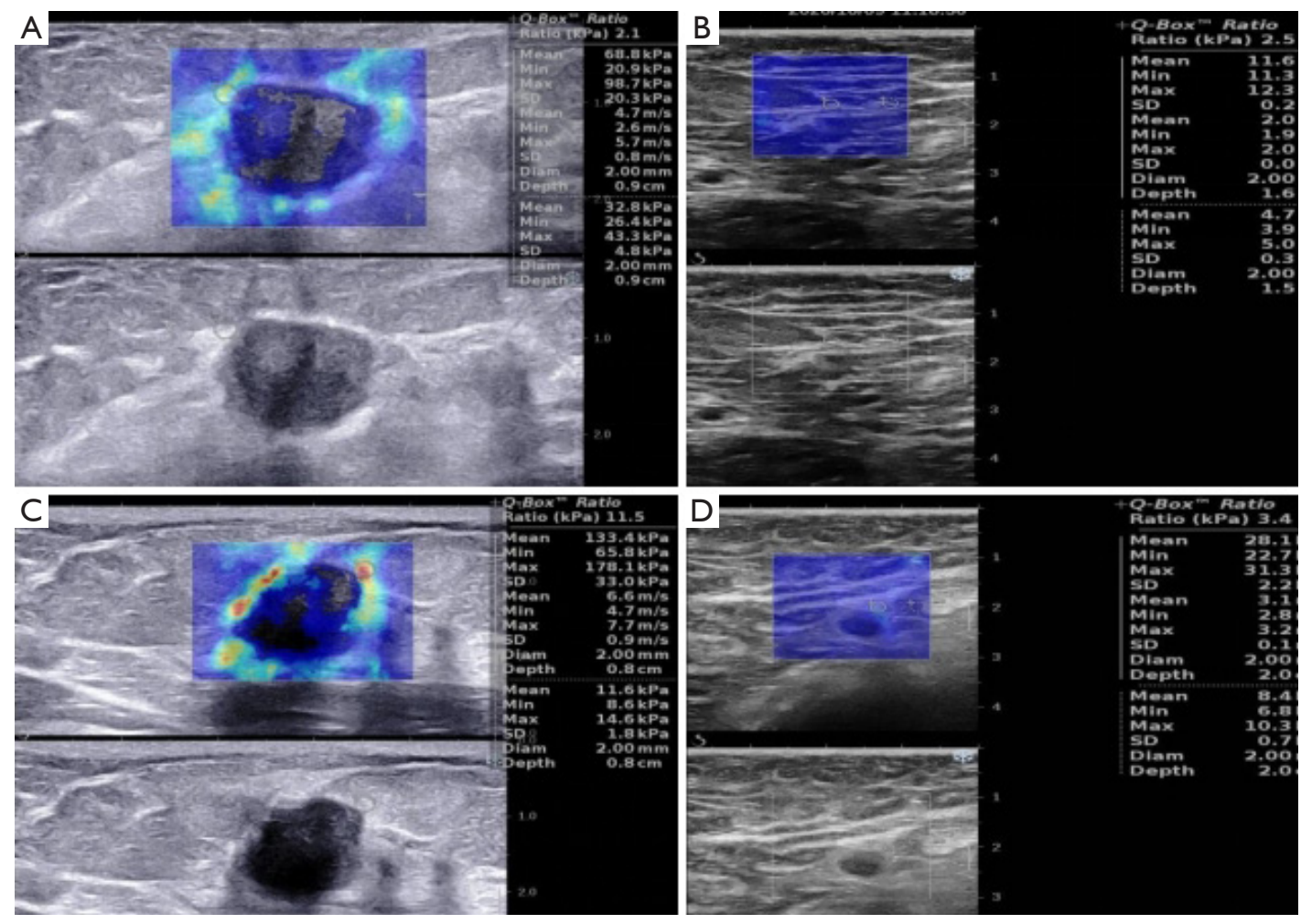

Figure 2 The SWE values in the limited nodal burden group and the high nodal burden group. (A,B) Limited nodal burden group images in a 45-year-old woman with invasive ductal carcinoma and one axillary lymph node metastasis. (A) SWE values of tumor were $98.7 \mathrm{kPa}$ for Emax, $68.8 \mathrm{kPa}$ for Emean, $20.3 \mathrm{kPa}$ for Esd. (B) SWE values of ALN were 12.3 kPa for Emax, 11.6 kPa for Emean, 2.5 for Eratio, $0.2 \mathrm{kPa}$ for Esd. No suspicious ALN was found preoperatively. (C,D) high nodal burden group images in a 60-year-old woman with invasive ductal carcinoma and six ALNs metastasis. (C) SWE values of tuomr were $178.1 \mathrm{kPa}$ for Emax, $133.4 \mathrm{kPa}$ for Emean, $33.0 \mathrm{kPa}$ for Esd. (D) SWE values of the most suspicious ALN were $31.3 \mathrm{kPa}$ for Emax, $28.1 \mathrm{kPa}$ for Emean, 3.4 for Eratio, $2.2 \mathrm{kPa}$ for Esd. Three suspicious ALNs were found preoperatively. SWE, shear wave elastography; ALN, axillary lymph node; Emax, maximum stiffness; Emean, mean stiffness; Eratio, stiffness ratio; Esd, stiffness standard deviation. 
Table 5 The diagnostic performance of SWE for the prediction of high nodal burden group with the optimal cutoff values

\begin{tabular}{|c|c|c|c|c|c|c|c|}
\hline SWE & Cutoff value & AUC (95\% Cl) & Sen & Spe & ACC & PPV & NPV \\
\hline Emax, $\mathrm{kPa}$ & 119.52 & $0.642(0.562-0.722)$ & 0.843 & 0.385 & 0.457 & 0.204 & 0.929 \\
\hline Emean, $\mathrm{kPa}$ & 97.31 & $0.635(0.555-0.715)$ & 0.843 & 0.403 & 0.472 & 0.209 & 0.932 \\
\hline Esd, $\mathrm{kPa}$ & 19.38 & $0.646(0.567-0.726)$ & 0.647 & 0.615 & 0.620 & 0.239 & 0.903 \\
\hline Emax, $\mathrm{kPa}$ & 26.22 & $0.856(0.802-0.909)$ & 0.725 & 0.868 & 0.846 & 0.507 & 0.944 \\
\hline Emean, $\mathrm{kPa}$ & 19.79 & $0.841(0.784-0.898)$ & 0.804 & 0.773 & 0.778 & 0.398 & 0.955 \\
\hline Eratio & 2.32 & $0.762(0.832-0.691)$ & 0.725 & 0.678 & 0.685 & 0.296 & 0.930 \\
\hline Esd, $\mathrm{kPa}$ & 3.34 & $0.836(0.777-0.896)$ & 0.647 & 0.886 & 0.849 & 0.516 & 0.931 \\
\hline
\end{tabular}

SWE, shear wave elastography; ALN, axillary lymph nodes; AUC, area under the curve; Sen, sensitivity; Spe, specificity; ACC, accuracy; PPV, positive predictive value; NPV, negative predictive value; Emax, maximum stiffness; Emean, mean stiffness; Eratio, stiffness ratio; Esd, stiffness standard deviation.
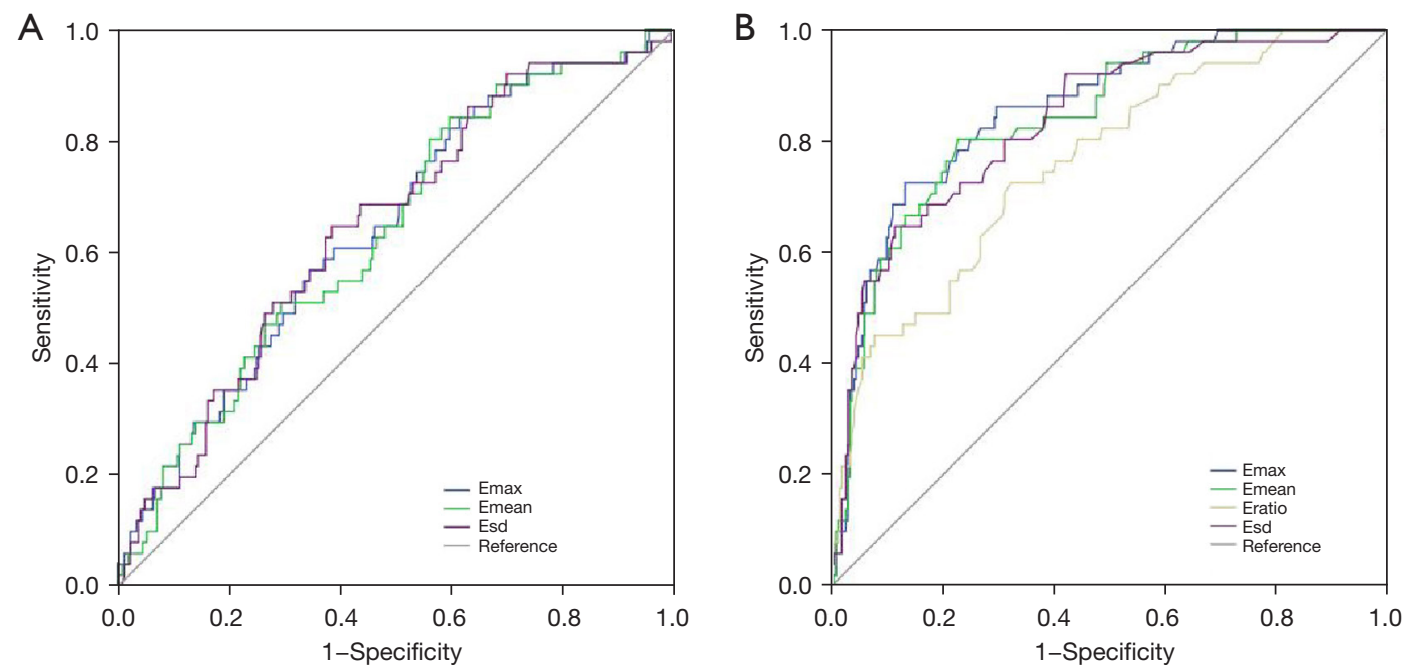

Figure 3 ROC curves for (A) Emax, Emean, Esd of tumor and (B) Emax, Emean, Eratio, Esd of ALN to diagnosis high nodal burden of IBC. The Emax of ALN has reliable application value in the differential diagnosis of lymph node burden in IBC (AUC =0.856; 95\% CI: 0.802-0.909). Emax, maximum stiffness; Emean, mean stiffness; Esd, stiffness standard deviation; ROC, receiver operating characteristic; ALN, axillary lymph node; IBC, invasive breast cancer; AUC, area under the curve; CI, confidence interval.

for high nodal burden groups. We verified that the concentrations of ALN cortical thickness $\geq 5 \mathrm{~mm}$ and the suspicious number of ALN $\geq 3$ were higher in the high nodal burden group than others, and the suspicious number of ALN $\geq 3$ was an independent predictor for high nodal burden.

Without first discovering by ultrasound, those unusual lymph nodes present do not stand to gain from fine needle aspiration or core needle biopsy. SWE contains details on the stiffness of the tissue examined based on traditional ultrasound, which gives it a great benefit in the area of breast cancer detection. This research focuses on the overall evaluation of the existence of a high nodal burden by SWE observations of primary breast cancer, except those who do not require ALND, and presents a significant alert to sonographers prior to axillary exams. The burden status was 
again determined by the assessment of the elastography of the lymph node. We explored the use of SWE for tumor and ALN assessment and discovered that all elasticity indices in the high nodal burden group were substantially higher than the limited nodal burden group, except for the tumor Eratio value. The median Emax and Emean in tumor, and the median Esd in ALN were independently associated with high nodal burden. Evans et al. (12) recorded that the median Emean of IBC had 3 nodal statuses: $105 \mathrm{kPa}$ for the nodenegative group, $130 \mathrm{kPa}$ for the $1-3$ node-positive group, and $149 \mathrm{kPa}$ for the 4 or more node-positive group, but did not present the optimal cutoff values. Since the subsets of the sample are different, my median findings for Emean are smaller than for the research $(106.7 \mathrm{kPa}$ for the limited nodal burden group, $123.9 \mathrm{kPa}$ for high nodal burden group). This disparity may be due to patient inclusion requirements. Furthermore, the findings are influenced by the probe and setting of the ultrasonic instrument and by the operator's manipulation.

We perceived that Emax of ALN has dependable application value in the diagnosis of lymph node burden in IBC. Detective performance of SWE characteristics of metastatic ALN in another study (27) was similar to ours, with the highest cutoff value being $25.8 \mathrm{kPa}$ for Emax, $18.7 \mathrm{kPa}$ for Emean, 2.7 for Eratio, 4.0 for Esd. To put it another way, if they were tested for high nodal burden, their findings could be higher than ours. This is due to data bias since our research was confined to clinical T1-T2N0 patients and was not used in patients with clinical palpation positive ALN, the ALN is lower in scale than other patients. The magnitude of the lesion is known to influence the elastic value calculated by SWE, and the elastic value of the bigger lesions is higher (28-30).

This research has a range of drawbacks. This is unitary center research, and we do not know if this outcome can be repeated in other medical centers. The amount of high nodal burden group was limited, and more instances were required to validate the ROC curve. Potential bias existed in incorporation and omission criteria, and qualifying patients with neoadjuvant chemotherapy are not incorporated in the review. Diagnostic efficiency analysis of combined elastography for the high nodal burden group have not been carried out. Research (31) reveals that the qualitative SWE classification of ALN shows improved diagnostic efficiency than the quantitative SWE parameter in the differentiation between metastatic ALN and benign reactive ALN, which merits more study.

In conclusion, an Emax cutoff $26.22 \mathrm{kPa}$ of ALN, $72 \%$ of women with a high nodal burden of axillary disease would be detected, but if used for clinical decision making, $13 \%$ of women with a limited nodal burden disease would be potentially over treated. This information can enable us to properly ascertain this subcategory and can be used as one of the methods to improve decision-making in clinical applications.

\section{Acknowledgments}

Funding: None.

\section{Footnote}

Reporting Checklist: The authors have completed the STARD reporting checklist. Available at https://dx.doi. org/10.21037/qims-21-580

Conflicts of Interest: All authors have completed the ICMJE uniform disclosure form (available at https://dx.doi. org/10.21037/qims-21-580). The authors have no conflicts of interest to declare.

Ethical Statement: The authors are accountable for all aspects of the work in ensuring that questions related to the accuracy or integrity of any part of the work are appropriately investigated and resolved. The retrospective study was approved by the Institutional Ethics Review of Harbin Medical University Cancer Hospital and aligned with the Helsinki Declaration of 1964 and its corresponding revisions or equivalent ethical principles. The written consent of each patient participating in the research was waived.

Open Access Statement: This is an Open Access article distributed in accordance with the Creative Commons Attribution-NonCommercial-NoDerivs 4.0 International License (CC BY-NC-ND 4.0), which permits the noncommercial replication and distribution of the article with the strict proviso that no changes or edits are made and the original work is properly cited (including links to both the formal publication through the relevant DOI and the license). See: https://creativecommons.org/licenses/by-nc-nd/4.0/.

\section{References}

1. Wild CP, Weiderpass E, Stewart BW. editors. World Cancer Report: Cancer Research for Cancer Prevention. 
Lyon, France: International Agency for Research on Cancer, 2020.

2. Morrow M, Van Zee KJ, Patil S, Petruolo O, Mamtani A, Barrio AV, Capko D, El-Tamer M, Gemignani ML, Heerdt AS, Kirstein L, Pilewskie M, Plitas G, Sacchini VS, Sclafani LM, Ho A, Cody HS. Axillary Dissection and Nodal Irradiation Can Be Avoided for Most Node-positive Z0011-eligible Breast Cancers: A Prospective Validation Study of 793 Patients. Ann Surg 2017;266:457-62.

3. Mansel RE, Fallowfield L, Kissin M, Goyal A, Newcombe RG, Dixon JM, Yiangou C, Horgan K, Bundred N, Monypenny I, England D, Sibbering M, Abdullah TI, Barr L, Chetty U, Sinnett DH, Fleissig A, Clarke D, Ell PJ. Randomized multicenter trial of sentinel node biopsy versus standard axillary treatment in operable breast cancer: the ALMANAC Trial. J Natl Cancer Inst 2006;98:599-609.

4. Veronesi U, Paganelli G, Viale G, Luini A, Zurrida S, Galimberti V, Intra M, Veronesi P, Robertson C, Maisonneuve P, Renne G, De Cicco C, De Lucia F, Gennari R. A randomized comparison of sentinel-node biopsy with routine axillary dissection in breast cancer. $\mathrm{N}$ Engl J Med 2003;349:546-53.

5. Giuliano AE, Hunt KK, Ballman KV, Beitsch PD, Whitworth PW, Blumencranz PW, Leitch AM, Saha S, McCall LM, Morrow M. Axillary dissection vs no axillary dissection in women with invasive breast cancer and sentinel node metastasis: a randomized clinical trial. JAMA 2011;305:569-75.

6. Alkuwari E, Auger M. Accuracy of fine-needle aspiration cytology of axillary lymph nodes in breast cancer patients: a study of 115 cases with cytologic-histologic correlation. Cancer 2008;114:89-93.

7. Balu-Maestro C, Chapellier C, Carrier P, Darcourt J, Ettore F, Raoust I. Role of imaging in the evaluation of axillary nodes and metastatic disease from breast carcinoma. J Radiol 2005;86:1649-57.

8. Sianesi M, Ceci G, Ghirarduzzi A, Del Rio P, Guazzi A, Pisanelli B, Martella E, Ardizzoni A, Di Blasio B, Arcuri MF. Use of axillary ultrasonography in breast cancer: a useful tool to reduce sentinel node procedures. Ann Ital Chir 2009;80:315-8.

9. Ko KH, Jung HK, Kim SJ, Kim H, Yoon JH. Potential role of shear-wave ultrasound elastography for the differential diagnosis of breast non-mass lesions: preliminary report. Eur Radiol 2014;24:305-11.

10. Gweon HM, Youk JH, Son EJ, Kim JA. Clinical application of qualitative assessment for breast masses in shear-wave elastography. Eur J Radiol 2013;82:e680-5.
11. Lee EJ, Jung HK, Ko KH, Lee JT, Yoon JH. Diagnostic performances of shear wave elastography: which parameter to use in differential diagnosis of solid breast masses? Eur Radiol 2013;23:1803-11.

12. Shiina T, Nightingale KR, Palmeri ML, Hall TJ, Bamber JC, Barr RG, et al. WFUMB guidelines and recommendations for clinical use of ultrasound elastography: Part 1: basic principles and terminology. Ultrasound Med Biol 2015;41:1126-47.

13. Wen X, Yu X, Tian Y, Liu Z, Cheng W, Li H, Kang J, Wei T, Yuan S, Tian J. Quantitative shear wave elastography in primary invasive breast cancers, based on collagen-S100A4 pathology, indicates axillary lymph node metastasis. Quant Imaging Med Surg 2020;10:624-33.

14. Tourasse C, Dénier JF, Awada A, Gratadour AC, NessahBousquet K, Gay J. Elastography in the assessment of sentinel lymph nodes prior to dissection. Eur J Radiol 2012;81:3154-9.

15. Hammond ME, Hayes DF, Dowsett M, Allred DC, Hagerty KL, Badve S, et al. American Society of Clinical Oncology/College Of American Pathologists guideline recommendations for immunohistochemical testing of estrogen and progesterone receptors in breast cancer. J Clin Oncol 2010;28:2784-95.

16. Carter CL, Allen C, Henson DE. Relation of tumor size, lymph node status, and survival in 24,740 breast cancer cases. Cancer 1989;63:181-7.

17. Lim GH, Teo SY, Allen JC Jr, Chinthala JP, Leong LCH. Determining Whether High Nodal Burden in Early Breast Cancer Patients Can Be Predicted Preoperatively to Avoid Sentinel Lymph Node Biopsy. J Breast Cancer 2019;22:67-76.

18. Luo H, Mo Y, Zhong J, Zhang Y, Zhu L, Shi X, Chen Y. Preoperative Axillary Ultrasound Helps in the Identification of a Limited Nodal Burden in Breast Cancer Patients. Ultrasound Q 2020;36:173-8.

19. Alvarez S, Añorbe E, Alcorta P, López F, Alonso I, Cortés J. Role of sonography in the diagnosis of axillary lymph node metastases in breast cancer: a systematic review. AJR Am J Roentgenol 2006;186:1342-8.

20. Greer LT, Rosman M, Charles Mylander W, Liang W, Buras RR, Chagpar AB, Edwards MJ, Tafra L. A prediction model for the presence of axillary lymph node involvement in women with invasive breast cancer: a focus on older women. Breast J 2014;20:147-53.

21. Humphrey KL, Saksena MA, Freer PE, Smith BL, Rafferty EA. To do or not to do: axillary nodal evaluation after ACOSOG Z0011 Trial. Radiographics 
2014;34:1807-16.

22. Boland MR, Prichard RS, Daskalova I, Lowery AJ, Evoy D, Geraghty J, Rothwell J, Quinn CM, O'Doherty A, McDermott EW. Axillary nodal burden in primary breast cancer patients with positive pre-operative ultrasound guided fine needle aspiration cytology: management in the era of ACOSOG Z011. Eur J Surg Oncol 2015;41:559-65.

23. Pilewskie M, Mautner SK, Stempel M, Eaton A, Morrow M. Does a Positive Axillary Lymph Node Needle Biopsy Result Predict the Need for an Axillary Lymph Node Dissection in Clinically Node-Negative Breast Cancer Patients in the ACOSOG Z0011 Era? Ann Surg Oncol 2016;23:1123-8

24. Bedi DG, Krishnamurthy R, Krishnamurthy S, Edeiken BS, Le-Petross H, Fornage BD, Bassett RL Jr, Hunt KK. Cortical morphologic features of axillary lymph nodes as a predictor of metastasis in breast cancer: in vitro sonographic study. AJR Am J Roentgenol 2008;191:646-52.

25. Tateishi T, Machi J, Feleppa EJ, Oishi R, Furumoto N, McCarthy LJ, Yanagihara E, Uchida S, Noritomi T, Shirouzu K. In vitro B-mode ultrasonographic criteria for diagnosing axillary lymph node metastasis of breast cancer. J Ultrasound Med 1999;18:349-56.

26. Kim WH, Kim HJ, Lee SM, Cho SH, Shin KM, Lee SY, Lim JK. Prediction of high nodal burden with ultrasound and magnetic resonance imaging in clinically node-

Cite this article as: Li B, Zhao X, Wang Q, Jing H, Shao H, Zhang L, Cheng W. Prediction of high nodal burden in invasive breast cancer by quantitative shear wave elastography. Quant Imaging Med Surg 2022;12(2):1336-1347. doi: 10.21037/qims21-580 negative breast cancer patients. Cancer Imaging 2019;19:4.

27. Youk JH, Son EJ, Kim JA, Gweon HM. Pre-Operative Evaluation of Axillary Lymph Node Status in Patients with Suspected Breast Cancer Using Shear Wave Elastography. Ultrasound Med Biol 2017;43:1581-6.

28. Chang JM, Moon WK, Cho N, Yi A, Koo HR, Han W, Noh DY, Moon HG, Kim SJ. Clinical application of shear wave elastography (SWE) in the diagnosis of benign and malignant breast diseases. Breast Cancer Res Treat 2011;129:89-97.

29. Evans A, Whelehan P, Thomson K, McLean D, Brauer K, Purdie C, Jordan L, Baker L, Thompson A. Quantitative shear wave ultrasound elastography: initial experience in solid breast masses. Breast Cancer Res 2010;12:R104.

30. Youk JH, Gweon HM, Son EJ, Han KH, Kim JA. Diagnostic value of commercially available shear-wave elastography for breast cancers: integration into BI-RADS classification with subcategories of category 4. Eur Radiol 2013;23:2695-704.

31. Luo S, Yao G, Hong Z, Zhang S, Wang W, Zhang J, Zhang Y, Wu J, Zhang L, Cheng H, Hao Y, Li Y. Qualitative Classification of Shear Wave Elastography for Differential Diagnosis Between Benign and Metastatic Axillary Lymph Nodes in Breast Cancer. Front Oncol 2019;9:533. 